\title{
Do Surface Porosity and Pore Size Influence Mechanical Properties and Cellular Response to PEEK?
}

\author{
F. Brennan Torstrick BSc, Nathan T. Evans BSc, Hazel Y. Stevens BSc, \\ Ken Gall PhD, Robert E. Guldberg PhD
}

Published online: 6 May 2016

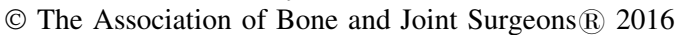

\begin{abstract}
Background Despite its widespread use in orthopaedic implants such as soft tissue fasteners and spinal intervertebral implants, polyetheretherketone (PEEK) often suffers from poor osseointegration. Introducing porosity can overcome this limitation by encouraging bone ingrowth; however, the corresponding decrease in implant strength can potentially reduce the implant's ability to bear physiologic loads. We have previously shown, using a single pore size, that limiting porosity to the surface of PEEK implants preserves strength while supporting in vivo
\end{abstract}

The institution of one or more of the authors (REG) has received, during the study period, funding from Vertera Spine, Inc (Atlanta, GA, USA). One or more of the authors (FBT, NTE, KG, REG) received payments or benefits, during the study period, an amount less than USD 10,000 USD from Vertera Spine, Inc. During these studies, one of the authors (NTE) was supported by the National Science Foundation Graduate Research Fellowship under Grant No. 2013162284. One of the authors (FBT) was supported by the National Center for Advancing Translational Sciences of the National Institutes of Health under Award No. UL1TR000454.

The content is solely the responsibility of the authors and does not necessarily represent the official views of the National Institutes of Health.

All ICMJE Conflict of Interest Forms for authors and Clinical Orthopaedics and Related Research ${ }^{\mathbb{R}}$ editors and board members are on file with the publication and can be viewed on request.

Clinical Orthopaedics and Related Research $₫$ neither advocates nor endorses the use of any treatment, drug, or device. Readers are encouraged to always seek additional information, including FDAapproval status, of any drug or device prior to clinical use. Each author certifies that his or her institution approved or waived approval for the reporting of this investigation and that all investigations were conducted in conformity with ethical principles of research.

This work was performed at the Georgia Institute of Technology, Atlanta, GA, USA.

Two of the authors (FBT, NTE) contributed equally to this work. osseointegration. However, additional work is needed to investigate the effect of pore size on both the mechanical properties and cellular response to PEEK.

Questions/purposes (1) Can surface porous PEEK (PEEK-SP) microstructure be reliably controlled? (2) What is the effect of pore size on the mechanical properties of PEEK-SP? (3) Do surface porosity and pore size influence the cellular response to PEEK?

Methods PEEK-SP was created by extruding PEEK through $\mathrm{NaCl}$ crystals of three controlled ranges: 200 to 312,312 to 425 , and 425 to $508 \mu \mathrm{m}$. Micro-CT was used to characterize the microstructure of PEEK-SP. Tensile, fatigue, and interfacial shear tests were performed to compare the mechanical properties of PEEK-SP with injectionmolded PEEK (PEEK-IM). The cellular response to PEEKSP, assessed by proliferation, alkaline phosphatase activity, vascular endothelial growth factor production, and calcium content of osteoblast, mesenchymal stem cell, and preosteoblast (MC3T3-E1) cultures, was compared with that of machined smooth PEEK and Ti6Al4V.

Results Micro-CT analysis showed that PEEK-SP layers possessed pores that were $284 \pm 35 \mu \mathrm{m}, 341 \pm 49 \mu \mathrm{m}$, and $416 \pm 54 \mu \mathrm{m}$ for each pore size group. Porosity and

F. B. Torstrick ( $₫)$, H. Y. Stevens, R. E. Guldberg Mechanical Engineering, Guldberg Musculoskeletal Research Laboratory, Georgia Institute of Technology, 315 Ferst Drive NW, Atlanta, GA 30332, USA

e-mail: brennan@gatech.edu

\section{N. T. Evans}

Materials Science and Engineering, Georgia Institute of Technology, Atlanta, GA, USA

K. Gall

Mechanical Engineering and Materials Science, Duke

University, Durham, NC, USA 
pore layer depth ranged from $61 \%$ to $69 \%$ and 303 to $391 \mu \mathrm{m}$, respectively. Mechanical testing revealed tensile strengths $>67 \mathrm{MPa}$ and interfacial shear strengths $>20$ $\mathrm{MPa}$ for all three pore size groups. All PEEK-SP groups exhibited $>50 \%$ decrease in ductility compared with PEEK-IM and demonstrated fatigue strength $>38 \mathrm{MPa}$ at one million cycles. All PEEK-SP groups also supported greater proliferation and cell-mediated mineralization compared with smooth PEEK and Ti6Al4V.

Conclusions The PEEK-SP formulations evaluated in this study maintained favorable mechanical properties that merit further investigation into their use in load-bearing orthopaedic applications and supported greater in vitro osteogenic differentiation compared with smooth PEEK and Ti6Al4V. These results are independent of pore sizes ranging $200 \mu \mathrm{m}$ to $508 \mu \mathrm{m}$.

Clinical Relevance PEEK-SP may provide enhanced osseointegration compared with current implants while maintaining the structural integrity to be considered for several load-bearing orthopaedic applications such as spinal fusion or soft tissue repair.

\section{Introduction}

Polyetheretherketone (PEEK) is a polymer widely used in orthopaedic and spinal applications such as soft tissue repair and spinal fusion devices as a result of its high strength, fatigue resistance, radiolucency, and favorable biocompatibility in osseous environments [25, 38, 45, 47, 50]. However, attributable in part to PEEK's relatively inert and hydrophobic surface, recent evidence has demonstrated that smooth PEEK can exhibit poor osseointegration [9, $25]$ and fibrous capsule formation around the implant [23, 34]. Lack of bone-implant contact can induce micromotion and inflammation that leads to fibrous layer thickening, osteolysis, and implant loosening [2, 13, 29, 37, 48]. Previous studies $[1,4,15,16,18,36]$ have shown that surface modifications such as plasma treatments, coatings, and composites can improve PEEK implant integration, yet many suffer practical limitations such as delamination, instability, and mechanical property tradeoffs.

The addition of porosity is a common modification to improve implant osseointegration by facilitating bone ingrowth and vascularization [27]. The importance of porosity for bone regeneration has been reviewed [24], and methods to create porous PEEK have been reported $[10,26,38,41,45,53]$. However, it is still unclear which aspects of the pore architecture (such as pore size, porosity, and pore layer thickness) control the mechanical and biological properties of porous PEEK implants. Furthermore, the overall volume of porosity and its spatial distribution throughout the implant should be considered as a result of the inverse relationship between porosity and strength of porous structures [12]. For example, limiting porosity to just a thin surface layer could facilitate adequate ingrowth for stable implant fixation while preserving the solid core for loadbearing.

Previously, our group described a surface porous PEEK (PEEK-SP) structure with high tensile strength, fatigue resistance, interfacial shear strength, and improved osseointegration compared with smooth PEEK [10]. Although the pore size investigated $(200-312 \mu \mathrm{m})$ was within the commonly accepted range for porous orthopaedic implants [24], additional work is needed to investigate whether the pore microstructure can be reliably controlled to yield other pore sizes and the subsequent effect of pore size on both the mechanical properties and biological responses to PEEK-SP.

We therefore asked the following three questions: (1) Can PEEK-SP microstructure be reliably controlled? (2) What is the effect of pore size on the mechanical properties of PEEK-SP? (3) Do surface porosity and pore size influence the cellular response to PEEK?

\section{Materials and Methods}

To evaluate the degree to which PEEK-SP microstructure can be reliably controlled, we processed the material using three porogen sizes and characterized the resulting microstructure using $\mu \mathrm{CT}$. To assess the influence of pore size on mechanical properties of PEEK-SP, we performed monotonic tensile tests to evaluate the strength, failure strain, and modulus; tensile fatigue tests to evaluate the fatigue life; and interfacial shear tests to evaluate the interfacial shear strength of the surface porous layer. Finally, to determine whether surface porosity and pore size influence the cellular response to PEEK, we cultured human femoral osteoblasts, human vertebral mesenchymal stem cells, and mouse preosteoblasts on PEEK-SP of all three pore sizes and compared the proliferation and osteogenic differentiation of the cells to smooth PEEK, Ti6Al4V, and tissue culture polystyrene (TCPS).

Medical-grade PEEK Zeniva ${ }^{\circledR} 500$ was provided by Solvay Specialty Polymers (Alpharetta, GA, USA). Medical-grade Ti6Al4V ELI (extra low interstitials) was purchased from Vulcanium (Northbrook, IL, USA) and the surface was fine grit-blasted (GB-13 blast media) and anodized according to AMS 2488D Type II by Danco (Arcadia, CA, USA). Sodium chloride was purchased from Sigma (St Louis, MO, USA).

Surface porous PEEK was created by extruding PEEK through the open spacing of sodium chloride crystals under heat and pressure as described previously [10]. By 
controlling the applied pressure and the time of processing, the flow distance was limited resulting in samples with a surface porosity and a solid core. After cooling, embedded sodium chloride crystals were leached in water leaving behind a porous surface layer. To control for pore size, sodium chloride was sieved into ranges of 200 to $312 \mu \mathrm{m}$, 312 to $425 \mu \mathrm{m}$, and 425 to $508 \mu \mathrm{m}$ using \#70, \#50, \#40, and \#35 US mesh sieves. Samples processed using each size range are referenced as PEEK-SP-250, PEEK-SP-350, and PEEK-SP-450, respectively. Injection-molded PEEK samples (PEEK-IM) were used as nonporous controls for mechanical testing. For cell studies, smooth nonporous PEEK samples were manufactured with a machined surface finish. Nonporous, machined smooth PEEK, PEEK-SP pore walls, and Ti6Al4V surfaces possessed a surface roughness $\left(S_{a}\right)$ of $0.59 \pm 0.12 \mu \mathrm{m}, 0.48 \pm 0.10 \mu \mathrm{m}$, and $0.55 \pm 0.02 \mu \mathrm{m}$, respectively, determined by laser confocal microscopy using a 50x/0.5-mm objective, $50-\mathrm{nm}$ step size and $\lambda_{\mathrm{c}}=20 \mu \mathrm{m}$ (LEXT OLS4000; Olympus, Waltham, MA, USA). $S_{a}$ values were not statistically different between groups ( $\mathrm{p}=0.28$, one-way analysis of variance).

Samples of PEEK-SP were evaluated using $\mu \mathrm{CT}$ ( $\mu$ CT 50; Scanco Medical, Brüttisellen, Switzerland) to measure the pore size, percent porosity, strut thickness, strut spacing, pore interconnectivity, and pore layer thickness. Samples were analyzed at $10-\mu \mathrm{m}$ voxel resolution with the scanner set at a voltage of $55 \mathrm{kVp}$ and a current of $200 \mu \mathrm{A}(\mathrm{n}=10)$. Contouring, the method of delineating the region of interest from areas not included in evaluation, was used to carefully select the pore layer volume and to minimize inclusion of nonporous volume. A global threshold was applied to segment PEEK from pore space for all evaluations. The global threshold was determined by analyzing the attenuation histograms for a representative sample of scans using an adaptive thresholding algorithm (Scanco) and confirmed visually before segmentation. Pore layer morphometric parameters were evaluated using direct distance transformation methods as described previously $[10,19]$. The depth of the pore layer was calculated as the mean thickness of the filled in contour around each pore layer. Pore size was measured from $\mu \mathrm{CT}$ cross-sections as the length of the pore diagonal (ImageJ; National Institutes of Health, Bethesda, MD, USA; $\mathrm{n}=375$ ).

Ultimate stress, failure strain, and elastic modulus were determined from monotonic tensile tests. Tensile tests were performed on Type I "dog-bone" specimens according to ASTM D638 at room temperature using a Satec (MTS, Eden Prairie, MN, USA) 20 kip ( 89 kN) servo-controlled, hydraulically actuated test frame $(n=5)$. The crosshead speed was $50 \mathrm{~mm} / \mathrm{min}$. Force displacement data as measured by the cross-head and validated by video (Canon HG10, Lake Success, NY, USA) and image processing software (ImageJ) were used to calculate ultimate stress, failure strain, and elastic modulus as well as to generate engineering stress-strain curves.

Fatigue tests were run at sequentially lower stresses (3\% decreases) below the ultimate stress of the samples to generate $\mathrm{S}-\mathrm{N}$ curves and determine the endurance limits of the respective samples. Fatigue tests were run on the same Satec test frame in axial stress control at a frequency of $1 \mathrm{~Hz}$ and an R-value (ratio of minimum load to maximum load) of 0.05 . Tests were run until failure or runout. Runout was defined as greater than 1,000,000 cycles.

For monotonic and fatigue results, two representations of stress for PEEK-SP were calculated: the first using the loadbearing area, $\mathrm{A}_{\mathrm{LB}}$ (the cross-sectional area of PEEK material in the gauge region, minus the pore area), and the second using the total area, $\mathrm{A}_{\mathrm{T}}$ (the cross-sectional area of the gauge region, including the pores). Use of total area produced stress values that assume void area contributed to loadbearing, and results consequently depend on pore layer thickness and volume fraction of porosity. Conversely, loadbearing area includes only the cross-sectional area of polymer material, including solid polymer and porous strut regions, ignoring void area in the porous layer.

Interfacial shear testing was used to assess the strength of the pore layer struts and predict their potential to withstand shearing loads experienced during implant insertion of after implantation. The test method was adapted from ASTM F1044-05 using Scotch-weld ${ }^{\text {TM }} 2214$ NonMetallic Filled (3 M, St Paul, MN, USA) as adhesive and a 30-kN load cell (Instron 5567, Norwood, MA, USA). A thin layer of adhesive was applied evenly to the surfaces of shear samples, and like faces were pressed together, clamped, and placed in a vacuum oven to cure at $121^{\circ} \mathrm{C}$ for 1 hour. The shear test fixtures were clamped in Instron jaws and adjusted to enable horizontal alignment of the shear sample. The plane of the adhesive was coincident with the axis of loading. Cured samples were placed into custom fixtures ensuring a tight clearance fit. The fixtures were pulled apart at $2.54 \mathrm{~mm} / \mathrm{min}$ until the interfacial surfaces of the samples were completely sheared. The interfacial shear stress was calculated based on the measured failure load and crosssectional area.

Proliferation of human femoral osteoblasts (hOB; ScienCell, Carlsbad, CA, USA) and human vertebral mesenchymal stem cells (hMSC; ScienCell) was evaluated on smooth nonporous PEEK, PEEK-SP-250, PEEK-SP350, PEEK-SP-450, Ti6Al4V, and TCPS $(\mathrm{n}=6)$ by measuring DNA incorporation of 5-ethynyl-2'-deoxyuridine (EdU) (Click-iT ${ }^{\mathbb{R}}$-EdU; ThermoFisher, Waltham, MA, USA). hOB and hMSC were seeded at 10,000 cells/ $\mathrm{cm}^{2}$ in growth media (ScienCell) and proliferation was measured at 48 hours per the manufacturer's instructions. Osteogenic differentiation was evaluated on each surface using clonal mouse preosteoblast cells (MC3T3-E1; 
ATCC, Manassas, VA, USA) as a result of their homogeneity, availability, and differentiation profile that is more similar to human osteoblasts than other in vitro models [7]. MC3T3 cells were seeded at 20,000 cells $/ \mathrm{cm}^{2}$ in growth media composed of $\alpha$-MEM (Life Technologies, Carlsbad, CA, USA) supplemented with $16.7 \%$ fetal bovine serum (Atlanta Biologicals, Lawrenceville, GA, USA) and 1\% penicillin-streptomycin-L-glutamine (Life Technologies). Cells were cultured under dynamic conditions using a rocker plate. After 3 days, cells reached confluence and half of all samples were switched to osteogenic media comprising growth media supplemented with $6 \mathrm{mM}$ $\beta$-glycerophosphate, $1 \mathrm{nM}$ dexamethasone, $50 \mathrm{ng} / \mathrm{mL}$ thyroxine, $50 \mu \mathrm{g} / \mathrm{mL}$ ascorbic acid 2-phosphate, and $1 \mathrm{nM}$ 1 $\alpha, 25$-dihydroxyvitamin D3 (Sigma, St Louis, MO, USA). The remaining half of the samples was maintained in growth media. Samples were cultured for 14 days after confluence, changing media every 3 to 4 days. At 14 days, samples undergoing assays for alkaline phosphatase (ALP) activity and DNA content were washed with phosphatebuffered saline (PBS) $\left(-\mathrm{Ca}^{2+} /-\mathrm{Mg}^{2+}\right)$, ultrasonically lysed in Triton X-100 (0.05\% in PBS), and subjected to one freeze-thaw cycle before further analysis. Samples assayed for calcium were washed with PBS $\left(-\mathrm{Ca}^{2+} /-\mathrm{Mg}^{2+}\right)$ and vortexed overnight at $4^{\circ} \mathrm{C}$ in $1 \mathrm{~N}$ acetic acid to solubilize calcium. ALP activity, an early osteogenic differentiation marker, was determined by colorimetric intensity of cell lysates exposed to p-nitrophenyl phosphate (Sigma) and was normalized to same-well DNA content determined by a Picogreen dsDNA assay (Life Technologies). Calcium deposition, a marker indicative of mineralization, in parallel cultures was determined by a colorimetric Arsenazo III reagent assay (Diagnostic Chemicals Ltd, Oxford, CT, USA). To determine the extent of noncell-mediated mineral deposition, the assay was also performed on acellular control samples and on samples seeded with a nonmineralizing cell line (Human Embryonic Kidney [HEK]; ATCC). HEK cells were seeded to reach confluency at the same 3-day time point as MC3T3 cultures. Both acellular and HEK controls were cultured under osteogenic conditions. Vascular endothelial growth factor (VEGF) production by MC3T3-E1 cells was measured from culture media at Day 14 after confluence using an enzyme-linked immunosorbent assay and normalized to same-well DNA content (R\&D Systems, Minneapolis, MN, USA).

Results of mechanical tests were analyzed using a oneway analysis of variance (ANOVA) and Tukey post hoc analysis (95\% confidence interval). In vitro assays were analyzed using a one-way ANOVA for EdU assays and a two-way ANOVA for all other assays. Tukey post hoc tests were used to compare all in vitro groups. All data are expressed as mean $\pm \mathrm{SD}$.

\section{Results}

\section{Can PEEK-SP Microstructure Be Controlled?}

Using $\mu \mathrm{CT}$ analysis, we found that pore morphology could be reliably controlled by varying the sodium chloride crystal size with the pores conforming to the porogen's cubic shape (Fig. 1). The data demonstrate that salt crystal
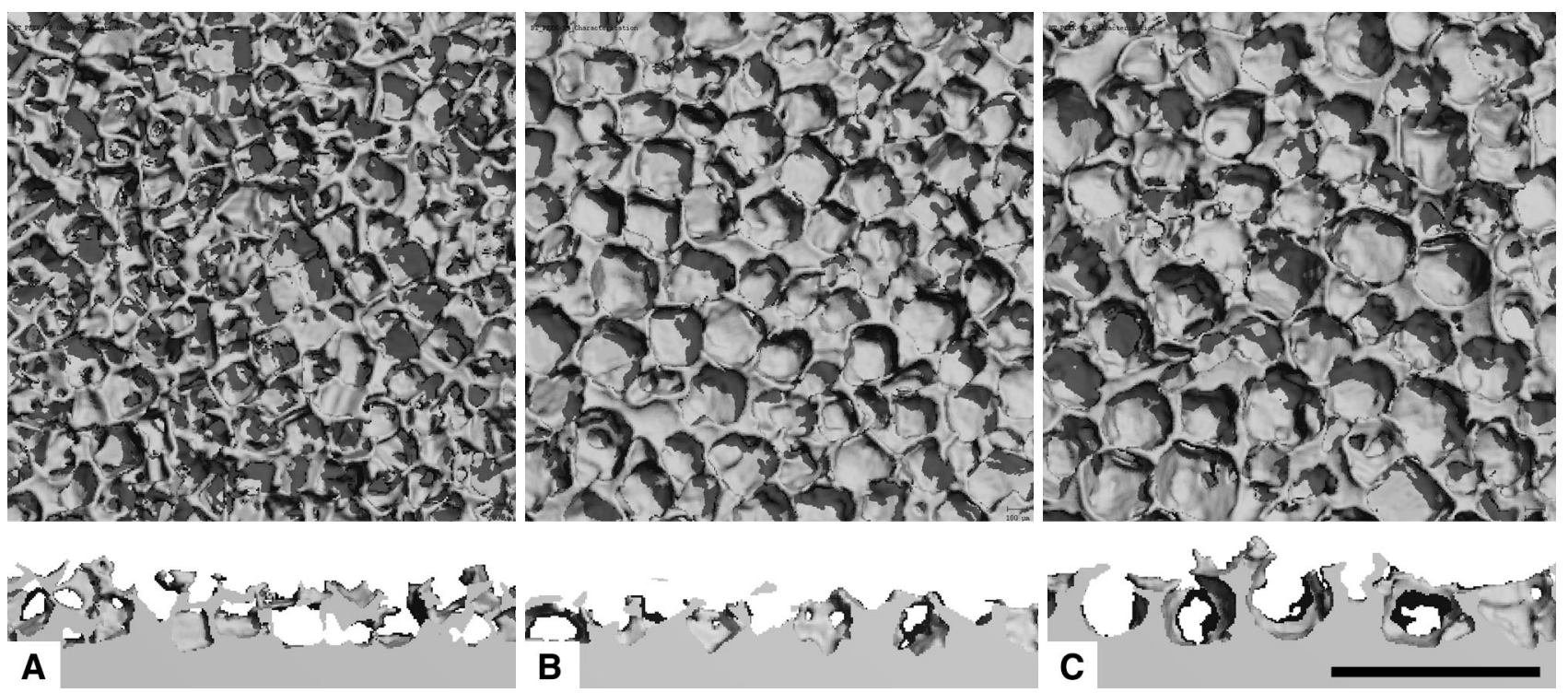

Fig. 1A-C Representative $\mu C T$ reconstructions of the surface and cross-section of PEEK-SP. (A) PEEK-SP-250, (B) PEEK-SP-350, and (C) PEEK-SP-450 are shown. 
Table 1. PEEK-SP pore layer morphometrics

\begin{tabular}{lllllll}
\hline Surface & Pore size $(\mu \mathrm{m})$ & Strut spacing $(\mu \mathrm{m})$ & Strut thickness $(\mu \mathrm{m})$ & Porosity $(\%)$ & Interconnectivity $(\%)$ & Layer thickness $(\mu \mathrm{m})$ \\
\hline PEEK-SP-250 & $284 \pm 35$ & $169 \pm 3$ & $73 \pm 8$ & $69 \pm 3$ & $99.9 \pm 0.04$ & $391 \pm 79$ \\
PEEK-SP-350 & $341 \pm 49^{*}$ & $208 \pm 5^{*}$ & $104 \pm 9^{*}$ & $61 \pm 3^{*}$ & $99.8 \pm 0.17$ & $303 \pm 29^{*}$ \\
PEEK-SP-450 & $416 \pm 54^{*}$, & $248 \pm 1^{*}$, & $119 \pm 14^{*},+$ & $62 \pm 4^{*}$ & $99.8 \pm 0.25$ & $342 \pm 38$ \\
\hline
\end{tabular}

Mean $\pm \mathrm{SD} ;{ }^{*} \mathrm{p}<0.01$ versus SP-250; ${ }^{\dagger} \mathrm{p}<0.05$ versus SP-350 (one-way analysis of variance, Tukey).

size can be used to reliably control the pore size of PEEK$\mathrm{SP} \quad(\mathrm{SP}-250=284 \pm 35 \mu \mathrm{m}, \quad \mathrm{SP}-350=341 \pm 49 \mu \mathrm{m}$, $\mathrm{SP}-450=416 \pm 54 \mu \mathrm{m}) \quad(\mathrm{p}<0.001) . \quad$ Porosity was slightly affected with SP-250 having marginally higher porosity $(69 \% \pm 3 \%)$ compared with SP-350 $(61 \% \pm 3 \%)$ and SP-450 $(62 \% \pm 4 \%)(\mathrm{p}<0.001)$. All three groups had high levels (>99\%) of pore interconnectivity (Table 1).

\section{Effect of Pore Size on Mechanical Properties}

Mechanical testing results showed that varying PEEK-SP pore size within the studied range had relatively little influence on tensile strength, interfacial shear strength, and ductility; however, the data suggest that larger pores (SP450) led to lower fatigue strength. Compared with the tensile strength of PEEK-IM $(97.7 \pm 1.0 \mathrm{MPa}$; $95 \%$ confidence interval [CI], 96.5-99.0), PEEK-SP showed no difference in tensile strength when normalized to $\mathrm{A}_{\mathrm{LB}}$ for PEEK SP-250 (96.1 $\pm 2.6 \mathrm{MPa}$; 95\% CI，93.4-98.9; $\mathrm{p}=0.458)$ and PEEK SP-450 (94.5 $\pm 1.4 \mathrm{MPa} ; 95 \% \mathrm{CI}$, 92.8-96.2; $\mathrm{p}=0.050)$, but there was a small decrease for the PEEK-SP-350 group (93.4 $\pm 1.5 \mathrm{MPa}$; 95\% CI, 91.595.2; $\mathrm{p}=0.006$ ) (Fig. 2). All pore sizes showed a decrease in ductility compared with PEEK-IM as indicated by a decrease in failure strain $(\mathrm{IM}=20.2 \% \pm 2.4 \%, 95 \% \mathrm{CI}$, 17.2-23.3; SP-250 $=7.8 \% \pm 2.2 \%$, 95\% CI, 5.4-10.2; SP-350 $=7.0 \% \pm 0.9 \%, \quad 95 \%$ CI, $5.9-8.0 ; \quad$ SP-450 $=$ $8.1 \% \pm 1.5 \%, 95 \%$ CI, 6.3-10.0) $(\mathrm{p}<0.001)($ Table 2). No difference was found in the modulus between PEEK-SP samples and PEEK-IM when using $\mathrm{A}_{\mathrm{LB}}$; however, differences were evident when normalized to $\mathrm{A}_{\mathrm{T}}(\mathrm{IM}=3.3 \pm$ $0.1 \mathrm{GPa}, 95 \% \mathrm{CI}, 3.2-3.5$; SP-250 $=2.5 \pm 0.3 \mathrm{MPa}, 95 \%$ CI, 2.1-2.8; SP-350 = 2.5 $\pm 0.2 \mathrm{MPa}, 95 \% \mathrm{CI}, 2.2-2.8$; $\mathrm{SP}-450=2.3 \pm 0.2 \mathrm{MPa}, 95 \% \mathrm{CI}, 2.0-2.6)(\mathrm{p}<0.001)$ (Table 2). Fatigue tests showed that surface porosity decreased the fatigue strength of PEEK with the difference being more qualitatively pronounced at higher cycles (lower cyclic stresses) (Fig. 3). Furthermore, PEEK-SP450 appears to have a lower fatigue strength than the PEEK-SP-250 material. Runout stress at one million cycles was $81.7 \mathrm{MPa}$ for PEEK-IM, $60.0 \mathrm{MPa}\left(\mathrm{A}_{\mathrm{LB}}\right)$ and 45.3 MPa $\left(\mathrm{A}_{\mathrm{T}}\right)$ for PEEK-SP-250, 54.1 MPa $\left(\mathrm{A}_{\mathrm{LB}}\right)$ and

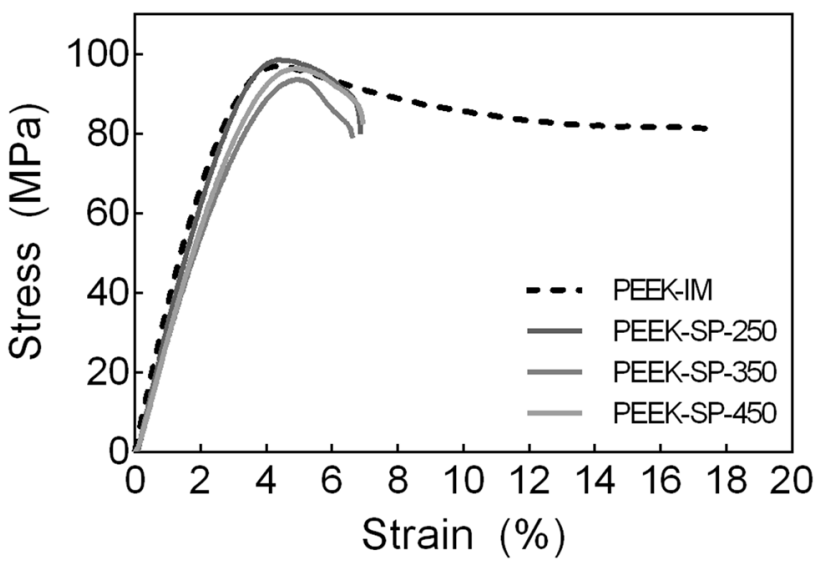

Fig. 2 Representative stress-strain curves of PEEK-IM and PEEK$\mathrm{SP}$ are shown.

66.3 MPa $\left(\mathrm{A}_{\mathrm{T}}\right)$ for PEEK-SP-350, and 53.4 MPa $\left(\mathrm{A}_{\mathrm{LB}}\right)$ and 38.0 MPa $\left(\mathrm{A}_{\mathrm{T}}\right)$ for PEEK-SP-450. The mean interfacial shear strength of PEEK-IM $(7.5 \pm 3.6 \mathrm{MPa}$; $95 \%$ CI, $1.7-$ 13.3) was less than PEEK-SP-250 $(24.0 \pm 2.3 \mathrm{MPa}$; $95 \%$ CI, 22.1-25.8), PEEK-SP-350 (21.4 $\pm 4.3 \mathrm{MPa} ; 95 \% \mathrm{CI}$, 17.4-25.4), and PEEK-SP-450 (22.4 $\pm 3.6 \mathrm{MPa}$; 95\% CI, 19.1-25.8) (p < 0.001) (Fig. 4). Different interfacial shear failure modes were apparent for smooth PEEK and PEEKSP. Smooth PEEK failed at the glue layer interface and the PEEK-SP samples failed within the porous network and within the solid region on the edges of some samples.

Influence of Surface Porosity on Cellular Response

Overall, cells cultured on PEEK-SP surfaces (regardless of pore size) exhibited a more differentiated phenotype than those cultured on smooth PEEK. All PEEK-SP groups had greater EdU DNA incorporation, which is indicative of increased cell proliferation, than smooth nonporous PEEK, Ti6Al4V, and TCPS surfaces for both hOB and hMSC cultures (hOB: smooth $=8752 \pm 4700$ counts, SP$250=27,065 \pm 12,812, \quad$ SP- $350=38,200 \pm 8874$, SP$450=32,810 \pm 12,257$, Ti6Al4V $=3583 \pm 924$, TCPS $=$ $1341 \pm 419 ;$ hMSC: smooth $=7343 \pm 5098$, SP-250 $=$ $33,738 \pm 16,485, \quad$ SP-350 $=28,937 \pm 1581, \quad$ SP-450 $=$ $33,636 \pm 12,341$, Ti6Al4V $=3685 \pm 636$, TCPS $=2474 \pm 274$ ) 
Table 2. Mechanical properties of PEEK-SP

\begin{tabular}{llllll}
\hline Surface & Tensile strength, $\mathrm{A}_{\mathrm{LB}}(\mathrm{MPa})$ & Tensile strength, $\mathrm{A}_{\mathrm{T}}(\mathrm{MPa})$ & Failure strain $(\%)$ & Modulus, $\mathrm{A}_{\mathrm{LB}}(\mathrm{GPa})$ & $\mathrm{Modulus}, \mathrm{A}_{\mathrm{T}}(\mathrm{GPa})$ \\
\hline PEEK-IM & $97.7 \pm 1.0$ & $97.7 \pm 1.0$ & $20.2 \pm 2.4$ & $3.3 \pm 0.1$ & $3.3 \pm 0.1$ \\
PEEK-SP-250 & $96.1 \pm 2.6$ & $71.1 \pm 2.2^{*}$ & $7.8 \pm 2.2^{*}$ & $3.4 \pm 0.3$ & $2.5 \pm 0.3^{*}$ \\
PEEK-SP-350 & $93.4 \pm 1.5^{*}$ & $70.3 \pm 3.4^{*}$ & $7.0 \pm 0.9^{*}$ & $3.3 \pm 0.2$ & $2.5 \pm 0.2^{*}$ \\
PEEK-SP-450 & $94.5 \pm 1.4$ & $67.0 \pm 1.5^{*}, \dagger$ & $8.1 \pm 1.5^{*}$ & $3.2 \pm 0.3$ & $2.3 \pm 0.2^{*}$
\end{tabular}

Mean $\pm \mathrm{SD}$; load-bearing area, $\mathrm{A}_{\mathrm{LB}}$, includes only the cross-sectional area of the polymer materials, ignoring void area; the total area, $\mathrm{A}_{\mathrm{T}}$, assumes void area contributes to load bearing area and is thus the measured sample dimensions; $* \mathrm{p}<0.01$ versus IM; ${ }^{\dagger} \mathrm{p}<0.01$ versus $\mathrm{SP}-250$ (one-way analysis of variance, Tukey).



Fig. 3 Stress versus loading cycle $(\mathrm{S}-\mathrm{N})$ curves comparing the fatigue behavior of PEEK-IM and PEEK-SP of different pore sizes. The arrows denote tests that were halted after reaching $1 \times 10^{6}$ cycles, which was defined as the runout cyclic stress.

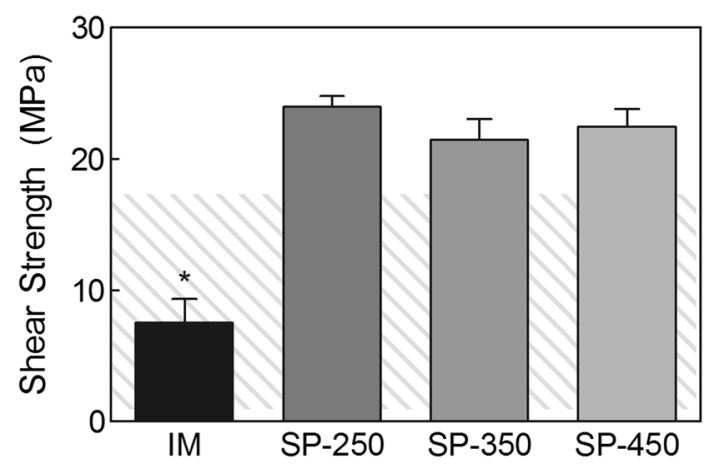

Fig. 4 Interfacial shear strength of PEEK-SP compared with the strength of the PEEK-IM contacting adhesive with the shear strength of trabecular bone shown in the shaded region $[14,17] . * \mathrm{p}<0.001$ versus all SP groups (one-way ANOVA, Tukey). Mean \pm SD.

$(\mathrm{p}<0.001$, except smooth versus SP-250 [hOB], $\mathrm{p}=$ 0.008) (Fig. 5). However, there were no differences found in EdU incorporation between pore sizes $(\mathrm{p}>0.148)$. Likewise, all PEEK-SP groups had similar calcium levels $(\mathrm{p}>0.779)$ that were much greater than smooth PEEK $(\mathrm{p}<0.001)$, Ti6Al4V $(\mathrm{p}<0.001)$, and TCPS $(\mathrm{p}<0.001)$ in osteogenic conditions (growth: smooth $=5.7 \pm 2.3 \mu \mathrm{g}, \quad$ SP-250 $=$ $5.2 \pm 1.4, \quad$ SP- $350=5.8 \pm 1.4, \quad$ SP- $450=5.3 \pm 0.5$,
Ti6Al4V $=3.0 \pm 0.2, \quad$ TCPS $=1.6 \pm 0.6 ; \quad$ osteogenic: smooth $=11.6 \pm 1.3, \quad$ SP-250 $=80.4 \pm 9.4, \quad$ SP-350 $=$ $80.9 \pm 6.7, \mathrm{SP}-450=85.2 \pm 9.4, \mathrm{Ti} 6 \mathrm{Al} 4 \mathrm{~V}=7.2 \pm 1.3$, TCPS $=12.5 \pm 5.2$; HEK: smooth $=6.7 \pm 2.8$, SP-250 $=$ $9.2 \pm 2.1, \quad$ SP- $-350=5.8 \pm 0.1, \quad$ SP- $450=7.7 \pm 0.1$, Ti6Al4V $=6.2 \pm 3.7, \quad$ TCPS $=2.4 \pm 0.1 ; \quad$ acellular: smooth $=3.9 \pm 1.7, \quad$ SP-250 $=8.1 \pm 5.1, \quad$ SP-350 $=$ $39.0 \pm 21.0, \quad$ SP- $450=13.3 \pm 8.8, \quad$ Ti6Al4V $=6.1 \pm$ 2.6, TCPS $=2.2 \pm 1.4$ ) (Fig. 6A). As expected, an overall reduction in calcium was seen on acellular controls and was further reduced in HEK groups, approaching levels detected in MC3T3 groups under growth media conditions. No differences in calcium were found between groups for MC3T3 cultures in growth media or HEK cultures $(p>0.723)$. Under osteogenic conditions, smooth PEEK supported fewer cells than TCPS (growth: smooth $=1.4 \pm 0.6 \mu \mathrm{g}$, SP-250 $=1.3 \pm 0.1, \quad$ SP-350 $=1.4 \pm 0.1, \quad$ SP-450 $=$ $1.6 \pm 0.4, \quad$ Ti6Al $4 \mathrm{~V}=2.7 \pm 0.7, \quad$ TCPS $=3.2 \pm 0.7$; osteogenic: smooth $=0.9 \pm 0.4, \mathrm{SP}-250=1.4 \pm 0.2$, SP$350=1.3 \pm 0.2, \mathrm{SP}-450=1.4 \pm 0.4, \mathrm{Ti} 6 \mathrm{Al} 4 \mathrm{~V}=1.5 \pm$ 0.4 , TCPS $=1.8 \pm 0.4)(\mathrm{p}=0.009)$ (Fig. 6B). In growth media, TCPS and Ti6Al4V surfaces supported more cells than all PEEK and PEEK-SP surfaces $(p<0.001)$. ALP activity of MC3T3 cells in osteogenic conditions at Day 14 was greater on TCPS compared with all other surfaces (growth: smooth $=0.27 \pm 0.08 \mu \mathrm{mol} \mathrm{pNP} / \mathrm{hr} / \mu \mathrm{g}$ DNA, SP-250 $=0.05 \pm 0.02, \quad$ SP-350 $=0.06 \pm 0.02, \quad$ SP$450=0.06 \pm 0.02, \quad$ Ti6Al4V $=0.13 \pm 0.03, \quad$ TCPS $=$ $0.19 \pm 0.07$; osteogenic: smooth $=3.10 \pm 1.31$, SP-250 $=$ $0.82 \pm 0.11, \quad$ SP-350 $=1.18 \pm 0.35, \quad$ SP-450 $=0.91 \pm$ 0.40$, Ti6Al4V $=2.66 \pm 1.02$, TCPS $=5.17 \pm 2.29)(\mathrm{p}<$ 0.001 , except smooth PEEK, $p=0.003$ ) and was greater for smooth PEEK and Ti6Al4V compared with all PEEKSP groups (smooth versus SP-250, $p<0.001$; smooth versus SP-350, $p=0.007$; smooth versus SP-450, $p=0.001$; Ti6Al4V versus SP-250, $\mathrm{p}=0.011$; Ti6Al4V versus SP$350, p=0.070 ;$ Ti6Al4V versus $\mathrm{SP}-450, \mathrm{p}=0.018$ ) (Fig. 6C). No differences in ALP activity were found under growth conditions ( $p>0.998)$. VEGF secretion of MC3T3 cells in growth media was greater on SP-250 compared with TCPS (growth: smooth $=392.4 \pm 93.0 \mathrm{pg} / \mu \mathrm{g}$ DNA, SP-250 $=507.6 \pm 41.7$, SP- $350=453.5 \pm 95.7$, SP-450 $=$ 


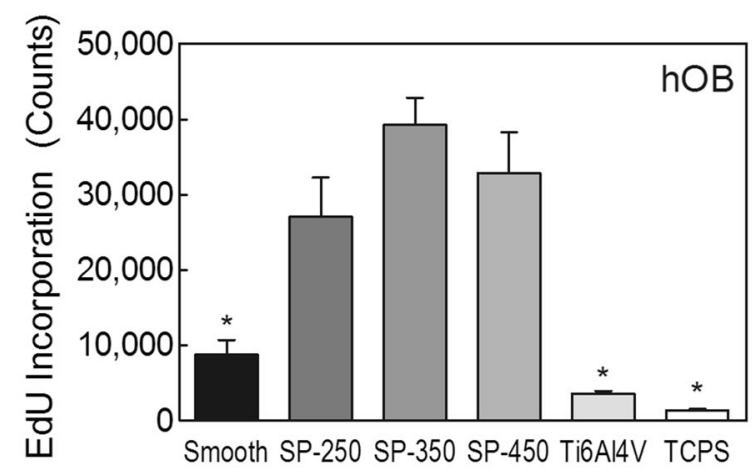

A

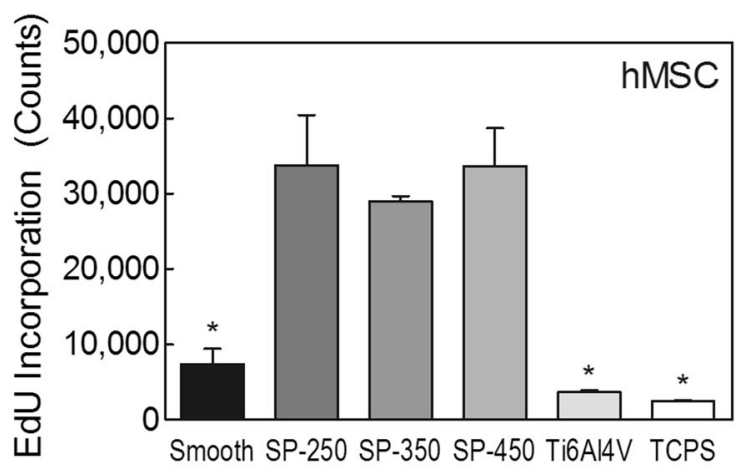

B

Fig. 5A-B (A) hOB and (B) hMSC proliferation measured by DNA incorporation of EdU 48 hours after seeding on smooth PEEK, PEEK-SP of various pore sizes, Ti6Al4V, and TCPS. ${ }^{*} \mathrm{p}<0.01$ versus all SP groups (one-way ANOVA, Tukey). Mean \pm SD.

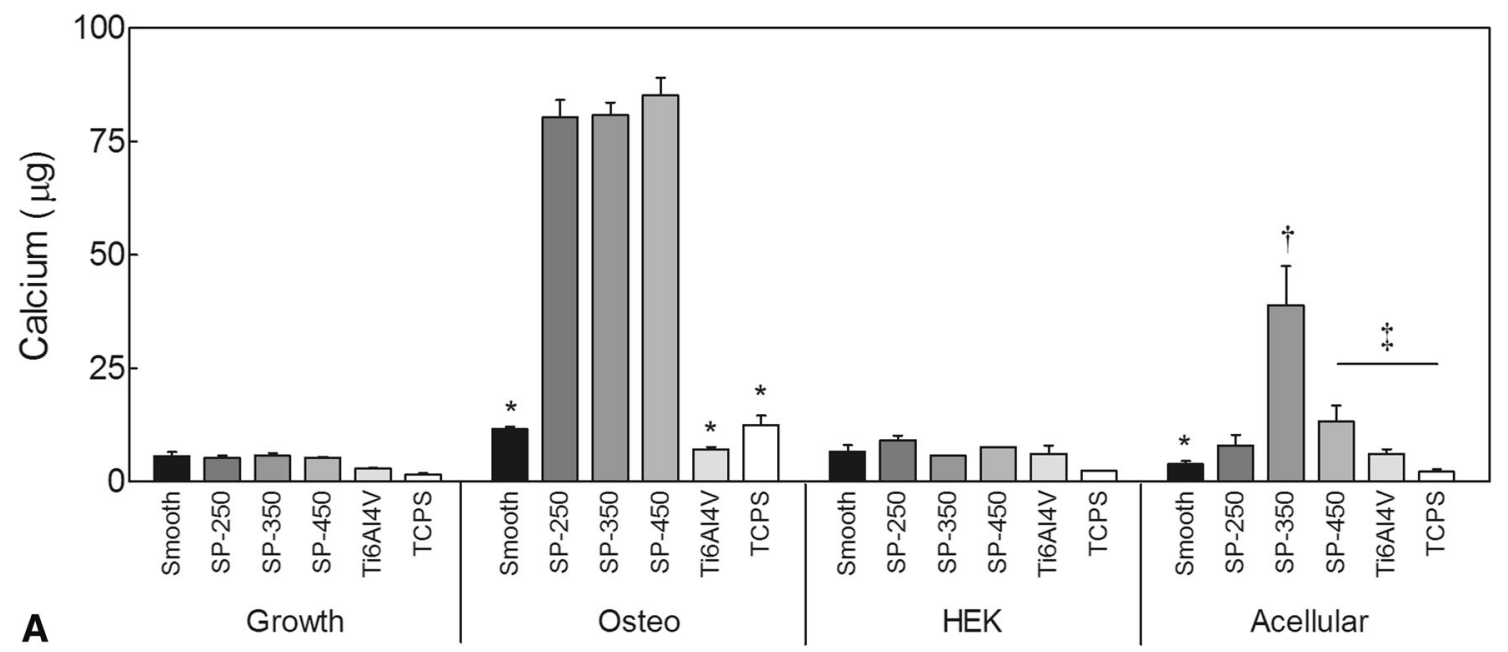

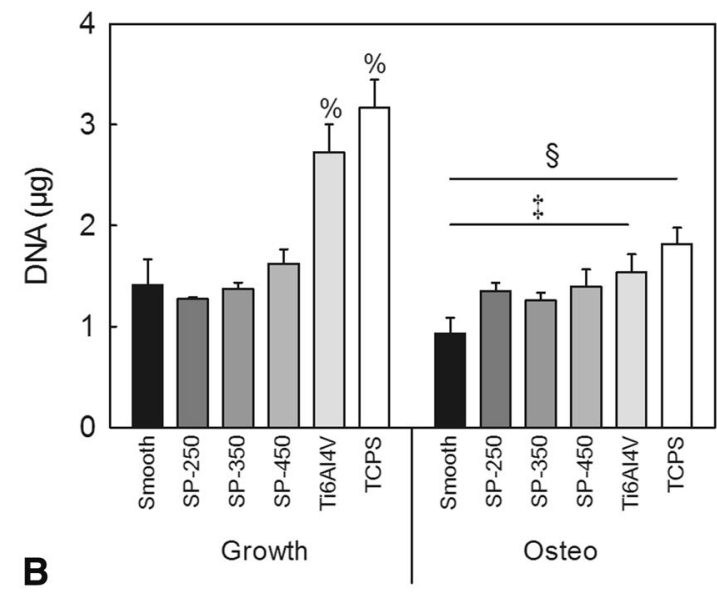

Fig. 6A-C (A) MC3T3 mediated calcium deposition on PEEK-SP groups compared with smooth PEEK, Ti6Al4V, and TCPS in growth media and osteogenic media. HEK cell and acellular cultures were used to determine the extent of noncell-mediated mineralization. Osteo: $* \mathrm{p}<0.001$ versus all SP groups; acellular: ${ }^{\dagger} \mathrm{p}<0.001$ versus all groups, ${ }^{\star} \mathrm{p}<0.05$ (two-way ANOVA, Tukey). (B) DNA content

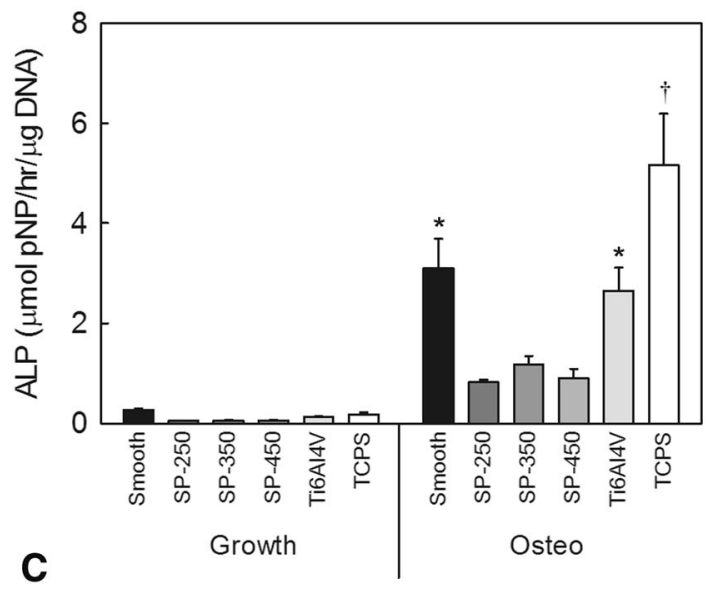

of parallel cultures on the same groups as in (A). Growth: \% $\mathrm{p}<0.001$ versus all PEEK groups; Osteo: ${ }^{\S} \mathrm{p}<0.01$ (two-way ANOVA, Tukey). (C) ALP activity of same-well cultures as (B). Osteo: ${ }^{*} \mathrm{p}<0.05$ versus all SP groups, ${ }^{\dagger} \mathrm{p}<0.01$ versus all groups, ${ }^{*} \mathrm{p}<0.05$ (two-way ANOVA, Tukey). Mean \pm SD. 
$430.1 \pm 54.0$, Ti6Al4V $=293.2 \pm 73.5$, TCPS $=252.7 \pm$ 61.5; osteogenic: smooth $=403.6 \pm 327.6, \mathrm{SP}-250=662.4 \pm$ 131.0, SP-350 = 692.2 $\pm 80.2, \quad \mathrm{SP}-450=656.2 \pm 62.8$, Ti6Al4V $=467.4 \pm 86.5$, TCPS $=309.7 \pm 76.8)(\mathrm{p}<0.001$, except smooth PEEK, $p=0.003)(p=0.037)$. Likewise, VEGF secretion in osteogenic media was greater on all PEEKSP groups compared with smooth PEEK and TCPS (smooth versus SP-250, $\mathrm{p}=0.022$; smooth versus $\mathrm{SP}-350, \mathrm{p}=0.008$; smooth versus SP-450, $\mathrm{p}=0.040$; TCPS versus SP-250, $\mathrm{p}<0.001$; TCPS versus SP-350, $\mathrm{p}<0.001$; TCPS versus SP$450, \mathrm{p}=0.001)$ (Fig. 7).

\section{Discussion}

Interest in improving PEEK's osseointegration has accelerated in recent years after numerous reports have described its inability in smooth form to facilitate bone apposition [9, 23, 25, 34, 51]. Reasons why this interest persists (as opposed to abandoning PEEK altogether) are often attributed to the other qualities of PEEK that make it favorable in orthopaedic and spinal applications, mainly its radiolucency, MRI compatibility, high strength, and fatigue resistance. In addition, the elastic modulus of PEEK is between that of cortical and trabecular human bone $[14,24]$, which may result in a lower risk of stress shielding and subsidence in applications such as spinal fusion when compared with other implant materials of the same geometry. We have previously shown that a surface porous PEEK implant facilitated osseointegration while

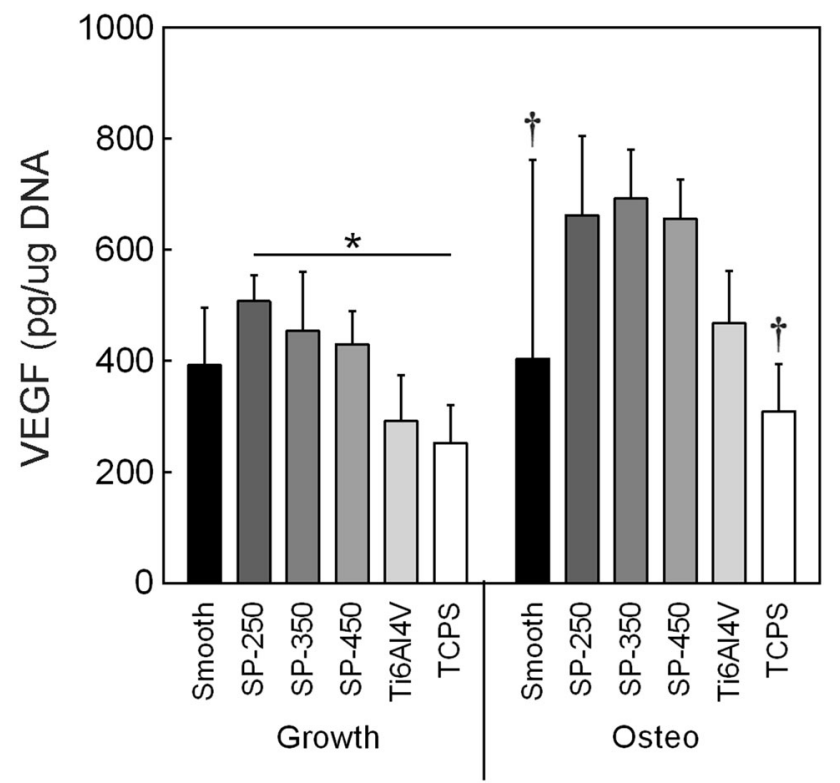

Fig. 7 VEGF secretion from MC3T3-E1 cells on PEEK-SP groups compared with machined smooth PEEK, Ti6Al4V, and TCPS in growth media and osteogenic media. ${ }^{\dagger} \mathrm{p}<0.05$ versus all SP groups, $* \mathrm{p}<0.05$ (two-way ANOVA, Tukey). Mean \pm SD. sufficiently preserving the mechanical properties of PEEK to be considered as a material for loadbearing orthopaedic implants [10]. Here we further investigated the PEEK-SP pore structure to compare the mechanical and biological performance of PEEK-SP with varied pore sizes.

Our study has a few limitations. First, percent porosity was not systematically studied and the range of pore sizes tested is rather small and only represents a twofold difference from the smallest to largest pores. However, the range of pore sizes that we tested are expected to cover the range that is clinically relevant [24]. Second, many applications can place implants under complex static or cyclic loading environments such as compression, torsion, and bending (or combinations thereof) that were not tested here. Surface flaws will have the most detrimental effect on the bulk properties in tension; thus, we believe that the data presented here represent a worst case scenario. However, further work is needed to understand the compressive properties of the surface porous layer. Additionally, all mechanical tests were performed in air at room temperature; however, we expect the behavior to be comparable in a more physiologic environment [11]. Third, we have not exclusively singled out pore size as a factor because other parameters also change with pore size (such as layer thickness) (Table 1).

We were able to reliably control pore size by selecting the size of salt crystal used as porogen. Reports investigating optimum pore sizes for various tissues generally recommend a pore size of 200 to $500 \mu \mathrm{m}$ for bone [3, 45]. Smaller pores may prevent cell infiltration or lead to insufficient vascularization and nutrient transport in vivo [24, 35]. Therefore, salt crystal sizes used in this study (200-508 $\mu \mathrm{m})$ were chosen to promote bone ingrowth and create a pore structure favorable for osseointegration. Microstructural characterization also showed that strut morphology parameters (spacing and thickness) were strongly influenced by crystal size, but were again highly consistent within the three groups, suggesting a high level of manufacturing reproducibility and control.

Mechanical characterization showed that pore size has relatively little influence on the mechanical properties of PEEK-SP within the evaluated size range; no differences were found between PEEK-SP of the three different pore sizes. The data demonstrate that although the loadbearing capacity for all pore sizes decreases when using $A_{T}$, this is mostly a geometric effect because their strength approaches that of PEEK-IM when calculated using $\mathrm{A}_{\mathrm{LB}}$. However, this will still influence the structural application of the material and is an important consideration in implant design. Tensile tests also revealed that failure strains were decreased to below $50 \%$ of PEEK-IM, consistent with previous studies that showed that polymers experience a decrease in failure strain in the presence of notches, 
whereas the effect on strength is typically marginal [42, 44]. There was no change in modulus with the addition of surface porosity when using $A_{L B}$. As a result of the cyclic loading experienced by orthopaedic implants and the often detrimental decrease in the fatigue resistance of polymers with surface flaws $[33,39,46]$, it was important to evaluate the fatigue resistance of PEEK-SP. All pore sizes demonstrated a high fatigue resistance at one million cycles when using $A_{L B}$ despite a decrease in endurance limit from injection-molded PEEK. It also appears that, qualitatively, PEEK-SP-450 had a slightly lower fatigue strength than PEEK-SP-250, in agreement with the finding that larger pores initiate more and larger fatigue cracks than small pores and therefore might have a greater effect on the fatigue life [21, 22]. Interfacial shear testing was also performed on PEEK-SP samples to investigate the mechanical integrity between the porous layer and solid core. No difference was found between PEEK-SP samples of different pore sizes. However, all PEEK-SP samples had higher interfacial shear strength than smooth PEEK, suggesting that any bone ingrowth will result in a mechanical interlock providing increased loadbearing area and higher bonding strength than smooth PEEK implants. Altogether, the mechanical properties of surface porous PEEK support its potential to bear physiologic loads with minimal risk of failure. For a clinical loading comparison, lumbar intervertebral discs experience loads of approximately 1000 to $3000 \mathrm{~N}$ depending on activity level, which is partially transferred to interbody implants after spinal fusion [32, 40, 49]. A simple stress calculation predicts that a PEEKSP implant under such loading would require 25 to $80 \mathrm{~mm}^{2}$ of surface area to remain in the elastic regime and below the fatigue strength at one million cycles (38 MPa). Most common spinal fusion implants exceed this size, lending support for use of PEEK-SP in spinal applications.

In vitro data support the ability of PEEK-SP to facilitate bone cell proliferation and differentiation. At early time points, cells exhibited increased proliferation on PEEK-SP compared with smooth PEEK, Ti6Al4V, and TCPS. During this proliferative phase, cells are thought to produce the extracellular matrix proteins required for matrix mineralization [28]. Therefore, the reduced cell proliferation on smooth PEEK, Ti6Al4V, and TCPS (Fig. 5) may have caused matrix production and mineralization to occur at later time points in comparison to PEEK-SP (Fig. 6A). This point is further evidenced by the higher ALP activity of cells on smooth PEEK, Ti6Al4V, and TCPS at Day 14 (Fig. 6C), suggesting that the cells and matrix were still preparing for mineralization. This is in contrast to cultures on PEEK-SP that were extensively mineralized by Day 14 and exhibited lower ALP activity levels, which can occur in heavily mineralized cultures and mature bone (Fig. 6C)
$[28,52]$. This increased mineralization seen in PEEK-SP cultures was clearly cell-mediated and not the result of the increased surface area of the porous layer. Additionally, cells grown on TCPS exhibited similar temporal trends in ALP activity and mineralization as in a previous report [6], suggesting that PEEK-SP accelerated osteoblast differentiation rather than smooth PEEK and Ti6Al4V causing delayed differentiation. One potential explanation for the initially increased cell proliferation on PEEK-SP is that the increased surface area effectively decreased the seeding density of cells, which could have facilitated greater cell proliferation at early time points [20, 54]. However, this increase in surface area and early proliferation did not translate to greater cell numbers at later time points (Fig. 6B). Although dynamic culture conditions likely enhanced nutrient transport within the pore layer [5], it is possible that cells on the surface of the porous layer caused more hypoxic conditions for the cells residing within the deeper pores. Although our previous data suggest that nutrient diffusion is not a limitation in vivo, where blood vessels are able to perfuse the pore network and allow bone to penetrate the full depth of the pore layer [10], hypoxia is known to influence osteoblast differentiation and endochondral ossification [8, 43]. This hypothesis is supported by the increased VEGF production of MC3T3 cells on PEEK-SP groups (Fig. 7), which is known to increase under hypoxic conditions [31, 43].

In this study, we demonstrated that surface porous PEEK can be created with a tunable microstructure. The results show that the introduction of a porous surface layer has the potential to provide an improved clinical outcome for polymeric implants while maintaining adequate loadbearing capacity. Unlike other methods to improve the osseointegration of PEEK implants such as fully porous PEEK scaffolds [30], PEEK-SP retains the bulk mechanical properties necessary for orthopaedic applications while potentially accelerating bone cell proliferation and differentiation compared with smooth PEEK and Ti6Al4V. Therefore, PEEK-SP may offer improved stability and performance over current implants at the critical boneimplant interface. Future studies will investigate the effect of pore size and pore layer depth on functional osseointegration in vivo within a preclinical animal model. In addition, further testing is needed to optimize the porosity to account for the tradeoff in bone ingrowth and compressive strength. To predict clinical performance in a spinal fusion application, implants possessing a PEEK-SP surface will undergo biomechanical testing to evaluate insertion force into the intervertebral disc space and the degree of subsidence into the endplates. This technology recently received FDA $510(\mathrm{k})$ clearance on the COHERE ${ }^{\mathrm{TM}}$ Cervical Interbody Fusion Device (Vertera Spine, Atlanta, GA, USA) and clinical data are forthcoming. 
Acknowledgments We thank Haley Harris BSc, for her assistance in sample processing, Cameron Irvin BSc, for his assistance in interfacial shear and fatigue testing, Angela Lin MSc, for her assistance with $\mu \mathrm{CT}$ analysis, and Jennifer Boothby BSc, and Sangeetha Thevuthasan for their help with in vitro studies.

\section{References}

1. Abu Bakar MS, Cheng MHW, Tang SM, Yu SC, Liao K, Tan CT, Khor KA, Cheang P. Tensile properties, tension-tension fatigue and biological response of polyetheretherketone-hydroxyapatite composites for load-bearing orthopedic implants. Biomaterials. 2003;24:2245-2250.

2. Athanasou NA, Quinn J, Bulstrode CJ. Resorption of bone by inflammatory cells derived from the joint capsule of hip arthroplasties. J Bone Joint Surg Br. 1992;74:57-62.

3. Boyan BD, Hummert TW, Dean DD, Schwartz Z. Role of material surfaces in regulating bone and cartilage cell response. Biomaterials. 1996;17:137-146.

4. Briem D, Strametz S, Schroder K, Meenen NM, Lehmann W, Linhart W, Ohl A, Rueger JM. Response of primary fibroblasts and osteoblasts to plasma treated polyetheretherketone (PEEK) surfaces. J Mater Sci Mater Med. 2005;16:671-677.

5. Cartmell SH, Porter BD, Garcia AJ, Guldberg RE. Effects of medium perfusion rate on cell-seeded three-dimensional bone constructs in vitro. Tissue Eng. 2003;9:1197-1203.

6. Czekanska EM, Stoddart MJ, Ralphs JR, Richards RG, Hayes JS. A phenotypic comparison of osteoblast cell lines versus human primary osteoblasts for biomaterials testing. J Biomed Mater Res A. 2014;102:2636-2643.

7. Czekanska EM, Stoddart MJ, Richards RG, Hayes JS. In search of an osteoblast cell model for in vitro research. Eur Cell Mater. 2012;24:1-17.

8. Dai J, Rabie AB. VEGF: an essential mediator of both angiogenesis and endochondral ossification. J Dent Res. 2007;86:937950.

9. Devine DM, Hahn J, Richards RG, Gruner H, Wieling R, Pearce SG. Coating of carbon fiber-reinforced polyetheretherketone implants with titanium to improve bone apposition. $J$ Biomed Mater Res B Appl Biomater. 2013;101:591-598.

10. Evans NT, Torstrick FB, Lee CS, Dupont KM, Safranski DL, Chang WA, Macedo AE, Lin A, Boothby JM, Whittingslow DC, Carson RA, Guldberg RE, Gall K. High-strength, surface-porous polyether-ether-ketone for load-bearing orthopedic implants. Acta Biomater. 2015;13:159-167.

11. Ferguson SJ, Visser JMA, Polikeit A. The long-term mechanical integrity of non-reinforced PEEK-OPTIMA polymer for demanding spinal applications: experimental and finite-element analysis. Eur Spine J. 2006;15:149-156.

12. Gibson LJ, Ashby MF. Cellular Solids: Structure and Properties. Cambridge, UK: Cambridge University Press; 1999.

13. Gittens RA, Olivares-Navarrete R, Schwartz Z, Boyan BD. Implant osseointegration and the role of microroughness and nanostructures: lessons for spine implants. Acta Biomater. 2014;10:3363-3371.

14. Goldstein SA. The mechanical properties of trabecular bone: dependence on anatomic location and function. $J$ Biomech. 1987;20:1055-1061.

15. Ha SW, Hauert R, Ernst KH, Wintermantel E. Surface analysis of chemically-etched and plasma-treated polyetheretherketone (PEEK) for biomedical applications. Surf Coat Technol. 1997;96:293-299.

16. Ha SW, Kirch M, Birchler F, Eckert KL, Mayer J, Wintermantel E, Sittig C, Pfund-Klingenfuss I, Textor M, Spencer ND,
Guecheva M, Vonmont H. Surface activation of polyetheretherketone (PEEK) and formation of calcium phosphate coatings by precipitation. J Mater Sci Mater Med. 1997;8:683-690.

17. Halawa M, Lee A, Ling R, Vangala S. The shear strength of trabecular bone from the femur, and some factors affecting the shear strength of the cement-bone interface. Arch Orthop Trauma Surg. 1978;92:19-30.

18. Han C-M, Lee E-J, Kim H-E, Koh Y-H, Kim KN, Ha Y, Kuh SU. The electron beam deposition of titanium on polyetheretherketone (PEEK) and the resulting enhanced biological properties. Biomaterials. 2010;31:3465-3470.

19. Hildebrand T, Laib A, Muller R, Dequeker J, Ruegsegger P. Direct three-dimensional morphometric analysis of human cancellous bone: microstructural data from spine, femur, iliac crest, and calcaneus. J Bone Miner Res. 1999;14:1167-1174.

20. Ishaug-Riley SL, Crane-Kruger GM, Yaszemski MJ, Mikos AG. Three-dimensional culture of rat calvarial osteoblasts in porous biodegradable polymers. Biomaterials. 1998;19:1405-1412.

21. Ishihara S, McEvily A, Goshima T, Kanekasu K, Nara T. On fatigue lifetimes and fatigue crack growth behavior of bone cement. J Mater Sci Mater Med. 2000;11:661-666.

22. James SP, Jasty M, Davies J, Piehler H, Harris WH. A fractographic investigation of PMMA bone cement focusing on the relationship between porosity reduction and increased fatigue life. J Biomed Mater Res. 1992;26:651-662.

23. Jockisch KA, Brown SA, Bauer TW, Merritt K. Biological response to chopped-carbon-fiber-reinforced peek. J Biomed Mater Res. 1992;26:133-146.

24. Karageorgiou V, Kaplan D. Porosity of 3D biomaterial scaffolds and osteogenesis. Biomaterials. 2005;26:5474-5491.

25. Kurtz SM, Devine JN. PEEK biomaterials in trauma, orthopedic, and spinal implants. Biomaterials. 2007;28:4845-4869.

26. Landy BC, Vangordon SB, McFetridge PS, Sikavitsas VI, Jarman-Smith M. Mechanical and in vitro investigation of a porous PEEK foam for medical device implants. J Appl Biomater Funct Mater. 2013;11:e35-e44.

27. Lewallen EA, Riester SM, Bonin CA, Kremers HM, Dudakovic A, Kakar S, Cohen RC, Westendorf JJ, Lewallen DG, van Wijnen AJ. Biological strategies for improved osseointegration and osteoinduction of porous metal orthopedic implants. Tissue Eng Part B Rev. 2015;21:218-230.

28. Lian JB, Stein GS. Concepts of osteoblast growth and differentiation: basis for modulation of bone cell development and tissue formation. Crit Rev Oral Biol Med. 1992;3:269-305.

29. Maniatopoulos C, Pilliar RM, Smith DC. Threaded versus porous-surfaced designs for implant stabilization in bone-endodontic implant model. J Biomed Mater Res. 1986;20:1309-1333.

30. Marcus Jarman-Smith, Mark Brady, Steven M. Kurtz, Cordara NM, Walsh WR. Porosity in polyaryletheretherketone. In: Kurtz SM, ed. PEEK Biomaterials Handbook. Kidlington, Oxford, UK: Elsevier Science; 2011:181-200.

31. Mayer H, Bertram H, Lindenmaier W, Korff T, Weber H, Weich $\mathrm{H}$. Vascular endothelial growth factor (VEGF-A) expression in human mesenchymal stem cells: autocrine and paracrine role on osteoblastic and endothelial differentiation. J Cell Biochem. 2005;95:827-839.

32. Nachemson A. Lumbar intradiscal pressure: experimental studies on post-mortem material. Acta Orthop. 1960;31:1-104.

33. Nielsen LE. Fatigue behavior of some filled polymers. J Compos Mater. 1975;9:149-156.

34. Nieminen T, Kallela I, Wuolijoki E, Kainulainen H, Hiidenheimo I, Rantala I. Amorphous and crystalline polyetheretherketone: Mechanical properties and tissue reactions during a 3-year follow-up. J Biomed Mater Res A. 2008;84:377-383. 
35. Oh SH, Park IK, Kim JM, Lee JH. In vitro and in vivo characteristics of PCL scaffolds with pore size gradient fabricated by a centrifugation method. Biomaterials. 2007;28:1664-1671.

36. Poulsson AHC, Eglin D, Zeiter S, Camenisch K, Sprecher C, Agarwal Y, Nehrbass D, Wilson J, Richards RG. Osseointegration of machined, injection moulded and oxygen plasma modified PEEK implants in a sheep model. Biomaterials. 2014;35:3717-3728.

37. Robotti P, Zappini G. Thermal plasma spray deposition of titanium and hydroxyapatite on polyaryletheretherketone implants. In: Kurtz SM, ed. PEEK Biomaterials Handbook. Kidlington, Oxford, UK: William Andrew; 2011:119-144.

38. Roeder R, Smith S, Conrad T, Yanchak N, Merrill C, Converse G. Porous and bioactive PEEK implants for interbody spinal fusion. Adv Mater Process. 2009;167:46-48.

39. Sauer JA, Richardson GC. Fatigue of polymers. Int J Fract. 1980;16:499-532.

40. Schultz AB, Andersson GB. Analysis of loads on the lumbar spine. Spine. 1981;6:76-82.

41. Siddiq AR, Kennedy AR. Porous poly-ether ether ketone (PEEK) manufactured by a novel powder route using near-spherical salt bead porogens: characterisation and mechanical properties. Mater Sci Eng C. 2015;47:180-188.

42. Sobieraj MC, Kurtz SM, Rimnac CM. Notch sensitivity of PEEK in monotonic tension. Biomaterials. 2009;30:6485-6494.

43. Steinbrech DS, Mehrara BJ, Saadeh PB, Greenwald JA, Spector JA, Gittes GK, Longaker MT. VEGF expression in an osteoblastlike cell line is regulated by a hypoxia response mechanism. Am J Physiol Cell Physiol. 2000;278:C853-C860.

44. Takano M, Nielsen LE. The notch sensitivity of polymeric materials. J Appl Polymer Sci. 1976;20:2193-2207.

45. Tan KH, Chua CK, Leong KF, Naing MW, Cheah CM. Fabrication and characterization of three-dimensional poly(ether-ether- ketone)/-hydroxyapatite biocomposite scaffolds using laser sintering. Proc Inst Mech Eng H. 2005;219:183-194.

46. Teoh SH. Fatigue of biomaterials: a review. Int J Fatigue. 2000;22:825-837.

47. Toth JM, Wang M, Estes BT, Scifert JL, Seim HB 3rd, Turner AS. Polyetheretherketone as a biomaterial for spinal applications. Biomaterials. 2006;27:324-334.

48. Wazen RM, Currey JA, Guo H, Brunski JB, Helms JA, Nanci A. Micromotion-induced strain fields influence early stages of repair at bone-implant interfaces. Acta Biomater. 2013;9:6663-6674.

49. Wilke HJ, Neef P, Caimi M, Hoogland T, Claes LE. New in vivo measurements of pressures in the intervertebral disc in daily life. Spine. 1999;24:755-762.

50. 50. Williams DF, McNamara A, Turner RM. Potential of polyetheretherketone (PEEK) and carbon-fibre-reinforced PEEK in medical applications. J Mater Sci Lett. 1987;6:188-190.

51. Wu S-H, Li Y, Zhang Y-Q, Li X-K, Yuan C-F, Hao Y-L, Zhang Z-Y, Guo Z. Porous titanium-6 aluminum-4 vanadium cage has better osseointegration and less micromotion than a poly-etherether-ketone cage in sheep vertebral fusion. Artif Organs. 2013;37:E191-E201.

52. Zhao G, Raines AL, Wieland M, Schwartz Z, Boyan BD. Requirement for both micron- and submicron scale structure for synergistic responses of osteoblasts to substrate surface energy and topography. Biomaterials. 2007;28:2821-2829.

53. Zhao Y, Wong HM, Wang W, Li P, Xu Z, Chong EYW, Yan CH, Yeung KWK, Chu PK. Cytocompatibility, osseointegration, and bioactivity of three-dimensional porous and nanostructured network on polyetheretherketone. Biomaterials. 2013;34:9264-9277.

54. Zhou YF, Sae-Lim V, Chou AM, Hutmacher DW, Lim TM. Does seeding density affect in vitro mineral nodules formation in novel composite scaffolds? J Biomed Mater Res A. 2006;78:183-193. 